\title{
Article \\ Genome-Wide Characterization and Evolutionary Analyses of Purple Acid Phosphatase (PAP) Gene Family with Their Expression Profiles in Response to Low Phosphorus Stresses in Moso Bamboo (Phyllostachys edulis)
}

\author{
Mengyan Zhou ${ }^{1}$, Wanting Chen ${ }^{1}$, Mingzhen Zhao ${ }^{1}$, Yachao $\mathrm{Li}^{1}$, Ming Li ${ }^{1,2}$ and Xia $\mathrm{Hu}^{1,3, *}$ \\ 1 Forestry College, Fujian Agriculture and Forestry University, Fuzhou 350002, China; \\ zhoumengyan@fafu.edu.cn (M.Z.); 2200428002@fafu.edu.cn (W.C.); 1200428021@fafu.edu.cn (M.Z.); \\ ycli@fafu.edu.cn (Y.L.); limingly@fafu.edu.cn (M.L.) \\ 2 Fujian Provincial Colleges and University Engineering Research Center of Plantation Sustainable \\ Management, Fuzhou 350002, China \\ 3 Key Laboratory of Integrated Pest Management in Ecological Forests, Fujian Province University, Fujian \\ Agriculture and Forestry University, Fuzhou 350002, China \\ * Correspondence: lake-autumn@fafu.edu.cn; Tel.: +86-591-8378-0261
}

Citation: Zhou, M.; Chen, W.; Zhao, M.; Li, Y.; Li, M.; Hu, X. Genome-Wide Characterization and Evolutionary Analyses of Purple Acid Phosphatase (PAP) Gene Family with Their Expression Profiles in Response to Low Phosphorus Stresses in Moso Bamboo (Phyllostachys edulis). Forests 2021, 12, 326. https://doi.org/ $10.3390 /$ f12030326

Received: 7 February 2021

Accepted: 8 March 2021

Published: 11 March 2021

Publisher's Note: MDPI stays neutral with regard to jurisdictional claims in published maps and institutional affiliations.

\section{Copyright: (C) 2021 by the authors.} Licensee MDPI, Basel, Switzerland. This article is an open access article distributed under the terms and conditions of the Creative Commons Attribution (CC BY) license (https:// creativecommons.org/licenses/by/ $4.0 /)$.

\begin{abstract}
Low phosphorus increases acid phosphatase activity and transfers soluble phosphorus from the underground to the above-ground, but also inhibits the growth and development of the Moso bamboo root system. Purple acid phosphatase (PAP), a kind of acid phosphatase, plays an important role in phosphorus $(\mathrm{P})$ uptake and metabolism. In our study of the Moso bamboo PAP gene family, we identified 17 Moso bamboo PAP genes (PePAP) in the entire genome and further analyzed their physical and chemical properties and functions PePAP. According to the analysis of the phylogenetic tree, special domains and conserved motifs, these 17 genes can be divided into four categories. The gene structure and conserved motifs are relatively conservative, but the 17 sequences of the PePAP domain are diverse. The prediction of the subcellular location indicated that PePAPs are mainly located in the secretory pathway. We have studied the expression levels of these PePAP in different organs, such as the roots, stems and leaves of Moso bamboo, and the results show that the expression of most PePAP genes in roots and stems seems to be higher than that in leaves. In addition to tissue-specific expression analysis, we also studied the expression of PePAPs under low phosphorus stress. Under such conditions, the PePAP genes show an increase in expression in the roots, stem and leaves, and the extent of this change varies between genes. In summary, our results reveal the evolution of the PePAP gene in the Moso bamboo genome and provide a basis for understanding the molecular mechanism of the PePAP-mediated response of Moso bamboo to low phosphorus.
\end{abstract}

Keywords: PAP genes; gene expression; phylogenetic relationships; low phosphorus stress; Moso bamboo

\section{Introduction}

Moso bamboo is China's most cultivated and economically valuable forest plant that is grown for shoots or for wood production, with an area of 4,677,800 hectares and ranking first in the world by the number of hectares planted [1]. Due to the "fast-growing" characteristics leading to rapid germination and fast growth, the Moso bamboo has a remarkably high yield and provides important resources for food, construction, papermaking and fiber [2]. The fast-growing bamboo shoots rely largely on the developed rhizome system to absorb nutrients from the soil [3]. However, the demand for nutrients for the rapid growth of Moso bamboo is very high, and the sufficient supply of soil nutrients, especially phosphorus $(\mathrm{P})$, limits the growth of these plants. Phosphorus is an essential mineral element for plant growth and development and plays an important role in energy transfer [4], 
signal transduction [5], photosynthesis and respiration [6]. Plants mainly absorb inorganic soluble phosphate in the soil through the root system but cannot directly absorb a large amount of organic phosphorus, such as phosphate ester and phosphate anhydride [7]. Due to a large amount of iron, aluminum and other mineral elements in the acid red soil of southern China, inorganic phosphorus mostly exists in the form of insoluble iron phosphate, aluminum phosphate and closed storage phosphorus wrapped by soil clay, which is difficult for the plant rhizosphere to reach for direct absorption and utilization. The current situation of "high reserve and low utilization" of soil phosphorus leads to a long-term deficiency of phosphorus, and forest tree species show a phenomenon of "genetics of phosphorus deficiency " [8,9]. At the same time, the application of phosphate fertilizer in production not only increased the cost and environmental pollution but also easily refixed the phosphate fertilizer into the soil, resulting in the utilization rate of phosphate fertilizer low (10-20\%) [10]. Especially in the Moso bamboo plantations in the acid red soil area of southern China that has been continuously planted for multiple generations, the deficiency of available soil phosphorus has become one of the key factors limiting the yield and quality improvement [11].

In the long-term evolution of plants, a series of morphological and physiological adaptation mechanisms have evolved to cope with a low phosphorus stress environment. Low phosphorus can induce a series of endogenous hormone secretion, acid phosphatase secretion [12], organic acid metabolism enhancement [13] and the expression of related genes [14], thereby promoting root elongation, organic acid and proton secretion [15]. These low phosphorus responses and adaptation mechanisms activate the phosphorus in the rhizosphere soil for plant utilization, enhance the root system's phosphorus-seeking ability and enhance the plant's phosphorus reuse efficiency [16]. Among them, the secretion of acid phosphatase from the roots can help plants activate rhizosphere organic phosphorus and release soluble inorganic phosphorus that can be absorbed and utilized by roots, which is one of the key response mechanisms of plants to low phosphorus stress. Studies have shown that, under low phosphorus stress, plants can induce the synthesis of purple acid phosphatase and the expression of phosphorus starvation-related genes and activate the functional response of related stress response proteins and transporters [17].

Purple acid phosphatase (PAP) is a kind of acid phosphatase that widely exists in microorganisms, plants and animals, and is a member of the metallophosphatase family [14]. The structure of PAPs is highly conserved, and the protein contains five conserved domains (the underline indicates seven metal paired amino acid residues), namely $\underline{D} X G / G \underline{D} X X \underline{Y} / G \underline{N H}(\mathrm{D} / \mathrm{E}) / \mathrm{VXX} \underline{\mathrm{H}} / \mathrm{G} \underline{\mathrm{H} X \underline{H}}$ [18]. The seven metal paired amino acid residues contained in the conservative domain can interact with metal ions, such as $\mathrm{Fe}^{3+}-\mathrm{Fe}^{2+} / \mathrm{Mn}^{2+} / \mathrm{Zn}^{2+}$, to form a catalytic center, and the catalytic site contains characteristic beta-alpha-beta-alpha-beta folding [17]. The biochemical characteristics, which are purple or pink in aqueous solution and l-tartaric acid, have no obvious inhibitory effect on its activity [19]. Under weak acidity ( $\mathrm{pH} \mathrm{4-7),} \mathrm{PAPs} \mathrm{can} \mathrm{catalyze} \mathrm{the} \mathrm{hydrolysis} \mathrm{of} \mathrm{phos-}$ phate monoester and anhydride organic matter (such as Adenine nucleoside triphosphate, Adenosine Diphosphate and glycolipid) to release the corresponding alcohol and inorganic phosphorus [20]. According to the molecular weight and interaction mode of purple acid phosphatase, PAPS can be divided into two categories: one is homodimeric PAPs with a molecular weight of about $55 \mathrm{kDa}$; the other is contain PAPs with a molecular weight of about $35 \mathrm{kDa}$ [21]. Homodimeric PAPs include N-terminal and C-terminal domains and have high homology with PAPs found in fungi and mycobacteria; only C-terminal PAPs only have a C-terminal domain, which is closer to the PAPs from animals [22]. Under low phosphorus stress, the activity of PAPs synthesized by plants with high phosphorus utilization efficiency significantly increases, and the enzymes are secreted out of the plant root cell membrane to activate the organic phosphorus around the rhizosphere, which effectively improves the plant's utilization of phosphorus [23,24]. The analysis of purple acid phosphatase in Arabidopsis thaliana, soybean (Glycine max Merr.) and rice (Oryza sativa L.) showed that there are 29 PAP genes in A. thaliana, 28, of which can be expressed in 
different tissues [25]; 26 PAP genes in rice [26]; and 35 PAP genes in soybean [27]. These $P A P$ genes, together with homologs from tobacco, maize, wheat and bean, were the subject of phylogenetic analysis that reveals that the PAP genes are divided into four families [19]: family I could be further divided into two subfamilies I-1 and I-2. Members of the I-1 subfamily participate in plant phosphorus and carbon metabolism pathways [28], I-2 subfamily proteins have phytase activity $[10,29]$; PAPs from family II participate in plant disease resistance, phosphorus starvation induction, cell development, metabolism and other biological processes [30]; There are few related studies concerning members of PAPS family III and IV, and it has been identified that GmPAP3 and PvPAP3 are related to plant responses to abiotic stress and phosphorus utilization efficiency [21]. The expression of most of the PAP genes are related to the inorganic phosphorus content in plants or to the plant response to environmental stress; however, the expression patterns of different PAP genes are not identical in all plants [31]. Studies on purple acid phosphatase and transcription factors in $A$. thaliana and rice have gradually revealed a series of molecular processes in the response mechanism of plants under low phosphorus stress; however, from woody plants, only a few species (e.g., Pinus massoniana Lamb.) have been studied by cloning PAP genes and analyzing their expression [32]. The functional analysis of Moso bamboo PAP genes and the regulation mechanism of PAP secretion have not yet been studied in-depth.

During the critical period of the rapid growth of Moso bamboo, phosphorus is one of the key factors limiting the yield and quality improvement of plantations. In the course of evolution, Moso bamboo plants have acquired such adaptations as a well-developed rhizome system and secretion PAPs to enhance the absorption and utilization efficiency of soil phosphorus. The study of PAP genes will help us to understand the evolutionary and functional mechanisms of bamboo plants to adapt to the environment and lay the foundation for future genetic improvement of Moso bamboo. In this study, we first investigated the root morphology, soluble phosphorus content and acid phosphatase activity of Moso bamboo under low phosphorus stress. Then, the PAP gene family in the whole-genome of Moso bamboo was studied. Seventeen PAP genes were identified in the Moso bamboo genome. The physical and chemical properties, phylogenetic relationship, gene structure, conserved domains and cis-acting elements of Moso bamboo PAPs were analyzed. The PAP gene expression profiles in different root and leaf tissues under low phosphorus stress were studied.

\section{Materials and Methods}

\subsection{Plant Materials, Growth Conditions and Treatments}

The seeds of Moso bamboo were thoroughly washed with sterile water and soaked in sterile water for $16 \mathrm{~h}$ and then germinated in the soil at $22{ }^{\circ} \mathrm{C}$ under long-day conditions (16 h of cool white, fluorescent light, photon flux of $70 \mu \mathrm{mol} \mathrm{m}^{-2} \cdot \mathrm{s}^{-1}$ ) [33]. Then, we irrigated the soil with $1 / 3 \times$ Hoagland's normal phosphorus $\left(1.0 \mathrm{mmol} / \mathrm{L} \mathrm{KH}_{2} \mathrm{PO}_{4}\right)$ nutrient solution every three days. For the treatment of low phosphorus stress, threeweek-old seedlings at the trilobal stage were thoroughly cleaned with sterile water, and the seedlings were soaked for $24 \mathrm{~h}$ in sterile water. Then, $1 / 3 \times$ Hoagland's nutrient solution with normal phosphorus $\left(1.0 \mathrm{mmol} / \mathrm{L} \mathrm{KH}_{2} \mathrm{PO}_{4}\right)$ and low phosphorus $(0.1 \mathrm{mmol} / \mathrm{L}$ $\mathrm{KH}_{2} \mathrm{PO}_{4}, 0.1 \mathrm{mmol} / \mathrm{L} \mathrm{KCl}$ ) was prepared. After soaking in sterile water for $24 \mathrm{~h}$, the seedlings were treated with normal phosphorus and low phosphorus Hoagland's nutrient solution for $0 \mathrm{~h}, 48 \mathrm{~h}, 96 \mathrm{~h}$ and $20 \mathrm{~d}$, respectively, in the plant hydroponic box. All experiments were repeated at least three times independently.

\subsection{Determination of Root Morphology, Phosphorus Content and Acid Phosphatase Activity}

After 20 days of low-phosphorus stress, the roots, stems and leaves of Moso bamboo were sampled and dried. A $0.2 \mathrm{~g}$ sample was weighed and ground into powder, and the total phosphorus content was determined in accordance with the Chinese forest soil total phosphorus standard methods (GB/T1. 1-1993). After 20 days of low-phosphorus 
stress, the seedlings with basically the same growth were screened, and the images were scanned by HP LaserJet 1536dnf MFP printer. Root length was measured by a root scanning analysis system (WinRHIZ0). According to the test method of related researchers [12], p-nitrophosphate phenol (pNPP) was measured to quantify the secretory acid phosphatase activity associated with roots. Roots and leaves excised from seedlings grown in normal phosphorus and low phosphorus nutrient solution for $0 \mathrm{~h}, 48 \mathrm{~h}$, and $96 \mathrm{~h}$ were washed with double distilled water. We ground $0.2 \mathrm{~g}$ fresh leaves or roots into powder by liquid nitrogen quick freezing. We extracted ground plant material with $4 \mathrm{~mL}$ of extraction solution $(0.2 \mathrm{~mol} / \mathrm{L} \mathrm{NaAc}, \mathrm{pH} 5.2), 7200 \mathrm{r} / \mathrm{min}$, centrifuged at $4{ }^{\circ} \mathrm{C}$ for $25 \mathrm{~min}$. Then we pipetted $0.3 \mathrm{~mL}$ of the supernatant and added $0.9 \mathrm{~mL}$ of $0.2 \mathrm{~mol} / \mathrm{L} \mathrm{NaAc}(\mathrm{pH} 5.2)$ and $1 \mathrm{mmol} / \mathrm{L}$ p-nitrophosphate phenol ( $\mathrm{pNPP})$, respectively. The mixture was kept in a water bath at $37^{\circ} \mathrm{C}$ for $30 \mathrm{~min}$. The enzyme reaction was terminated by adding $1 \mathrm{~mL} 1 \mathrm{~mol} / \mathrm{L} \mathrm{NaOH}$ immediately, centrifuged at $4{ }^{\circ} \mathrm{C}$ for $25 \mathrm{~min}$ at $7200 \mathrm{r} / \mathrm{min}$. A UV-vis spectrophotometer measured the light absorption value at $405 \mathrm{~nm}$. Root-associated secretory acid phosphatase activity was expressed as $\mu \mathrm{g}(\mathrm{pNPP}) \cdot \mathrm{g}^{-1}(\mathrm{FW}) \cdot \mathrm{min}^{-1}$.

\subsection{Database Search for Moso Bamboo PAP Genes}

To identify the PAP genes, the genome and protein sequences of Moso bamboo were downloaded from the Bamboo GDB database (http:/ / www.bamboogdb.org/\#/download (accessed on 5 November 2020)) [34]. PAP protein sequences from $A$. thaliana and rice were obtained from previously published data [31]. We performed multiple sequence BLAST (https:/ / blast.ncbi.nlm.nih.gov/Blast.cgi (accessed on 5 November 2020)) and alignment with an expected value of 20. The HMMER profile of the PAPs domain from Pfam (http:/ / pfam.xfam.org/ (accessed on 5 November 2020)) was used to search the bamboo protein database with a threshold: e-values $<0.01$ [35]. The proteins encoded by PAP genes were analyzed with the National Center for Biotechnology Information CD-search (https: / / www.ncbi.nlm.nih.gov/Structure/cdd/wrpsb.cgi (accessed on 5 November 2020)) programs to determine whether they contain specific conserved PAP domains. After that, the redundant sequences without regions containing 5 con-

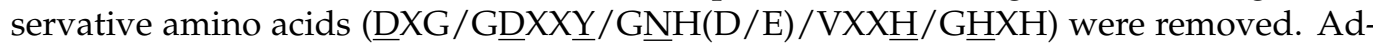
ditionally, PAP gene structures were obtained with the Gene Structure Display Server ( http:/ /gsds.cbi.pku.edu.cn/ (accessed on 5 November 2020)) [36]. The number of amino acids, molecular weights (MWs) and isoelectric points(PI) of Moso bamboo PAP proteins were predicted by ProtParam (https: / / web.expasy.org/protparam/ (accessed on 5 November 2020)) [37]. Protein subcellular localization was examined using WoLF PSORT (https://www.genscript.com/wolf-psort.html (accessed on 5 November 2020)) [5] and Plant-mPLoc (http: / / www.csbio.sjtu.edu.cn/bioinf/plant-multi/ (accessed on 5 November 2020)) [38].

\subsection{Phylogenetic, Conserved Domain and Motif Recognition Analyses}

Multi-sequence alignment of the PAP protein sequences was carried out by ClustalX [39], and the phylogenetic tree was constructed using MEGA (Version 7.0, Temple, Philadelphia, PA, USA ) by the neighbor-joining method (bootstrap analysis for 1000 replicates) [40]. Conserved motifs of PAPs were analyzed using the motif-based sequence analysis tools (MEME) (version 5.0.5, http://meme-suite.org/tools/meme (accessed on 5 November 2020)), with the following specific parameters: The maximum numbers of motifs, 20; optimum motif width was set at 30-50 [41]. Coding sequence (CDS) and genome sequences of PAPs were gained from the Moso bamboo genome (http:/ / www.bamboogdb.org/\#/ download (accessed on 5 November 2020)) and used for the gene structure (exon/intron) analysis, using GSDS 2.0 [42].

\subsection{Analysis of Regulatory Elements in the Promoter Regions of the PePAP Gene Family}

The upstream regions $(1.5 \mathrm{~Kb})$ of the translation initiation sites (ATG) of Moso bamboo PePAP genes were used as promoter fragments [43]. In addition, the elements were located 
in the promoter sequences, using the program PlantCARE online (http:/ /bioinformatics. psb.ugent.be/webtools/plantcare/html/ (accessed on 5 November 2020)).

\subsection{RNA Extraction and $q R T-P C R$}

Total RNA was extracted using the polysaccharide polyphenol plant total RNA extraction kit (TIAN GEN, Beijing, China)and use RNase-free DNase to process RNA. Reverse transcription was performed using the RevertAid First Strand cDNA Synthesis Kit (Thermo-Scientific, Wilmington, DE, USA) according to the manufacturer's instructions. The quantitative real-time PCR (qPCR) was performed using the NovoStart ${ }^{\circledR}$ SYBR qPCR SuperMix Plus (Novoprotein, Shanghai, China). Moreover, $0.1 \mu \mathrm{g}$ of cDNA template was used for real-time quantification. The gene-specific primers were designed through the online primer design website (https:/ / bioinfo.ut.ee/primer3-0.4.0/ (accessed on 5 November 2020)), and TIP41 genes that can be stably expressed in various tissues of bamboo were selected as internal references [37]. Gene expression levels were determined using the 2-delta-delta Ct method [44]. Three biological and technical replicates were carried out for each reaction, and a negative control was set to ensure the reproducibility of the results. All the primers used in the text for qRT-PCR are listed in Table S1.

\subsection{Statistical Analysis}

The SPSS Statistics Base software (version 25, Armonk, New York, NY, USA) was used for statistical analysis of significant differences. Significant differences were evaluated using one-way ANOVA and Turkey's test. The statistical significance for all tests was set at $p<0.05$. Figure 1, Figure 2, Figure 3 and Figure 8 were drawn using GraphPad (version 8, San Diego, CA, USA) software. Moreover, Table 1 and Figure 7 are drawn using Microsoft Excel (version 2016, Redmond, WA, USA) software.

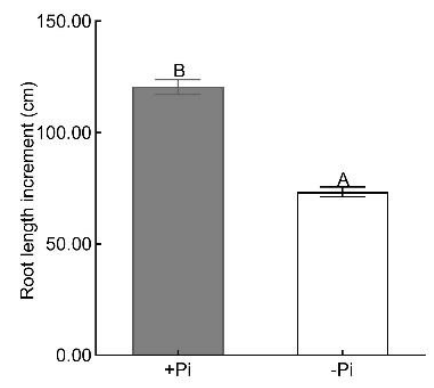

(a)

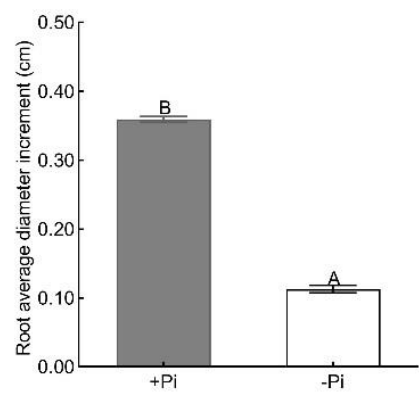

(c)

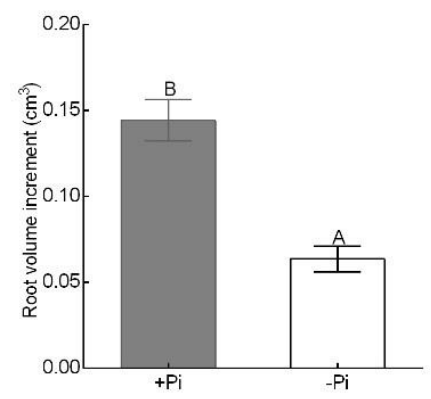

(b)

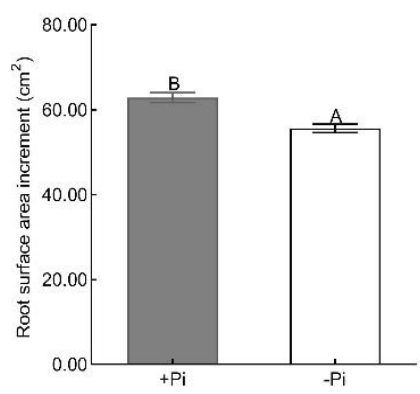

(d)

Figure 1. Effects of low phosphorus stress on the root system of Moso bamboo. (a) Increment of Moso bamboo root length. (b) Moso bamboo root volume increase. (c) Average root diameter increment of Moso bamboo. (d) Moso bamboo root surface area increase. Uppercase letters indicate that there is a significant difference between the normal phosphorus group and the low phosphorus stress group $(p<0.05)$. 


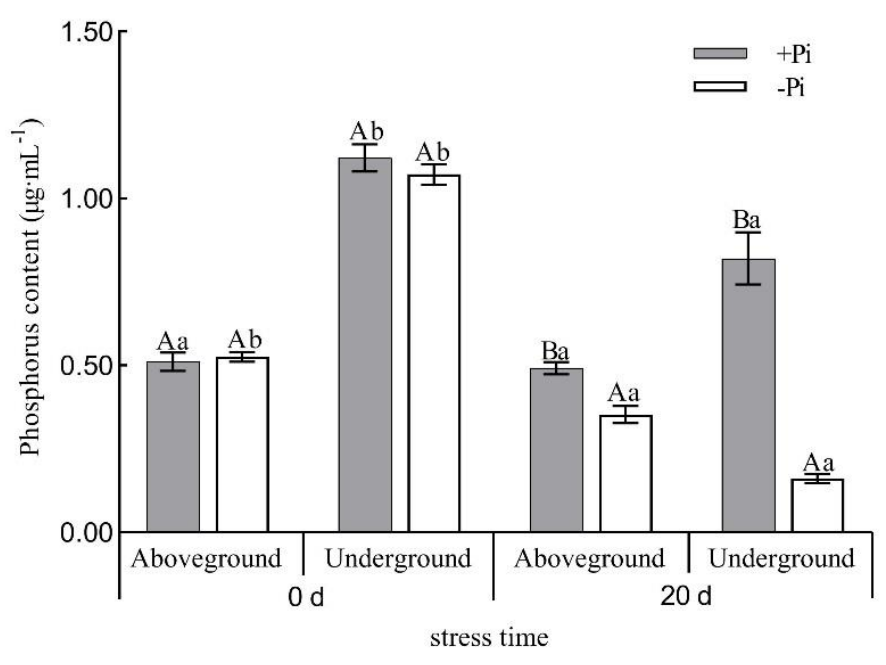

Figure 2. Phosphorus content of Moso bamboo above ground and underground. Uppercase letters indicate that under the same treatment time, there is a significant difference in phosphorus content between the normal phosphorus group and the phosphorus deficiency group. Lowercase letters indicate that the phosphorus content of the same phosphorus-treatment group is significantly different at different treatment times $(p<0.05)$.

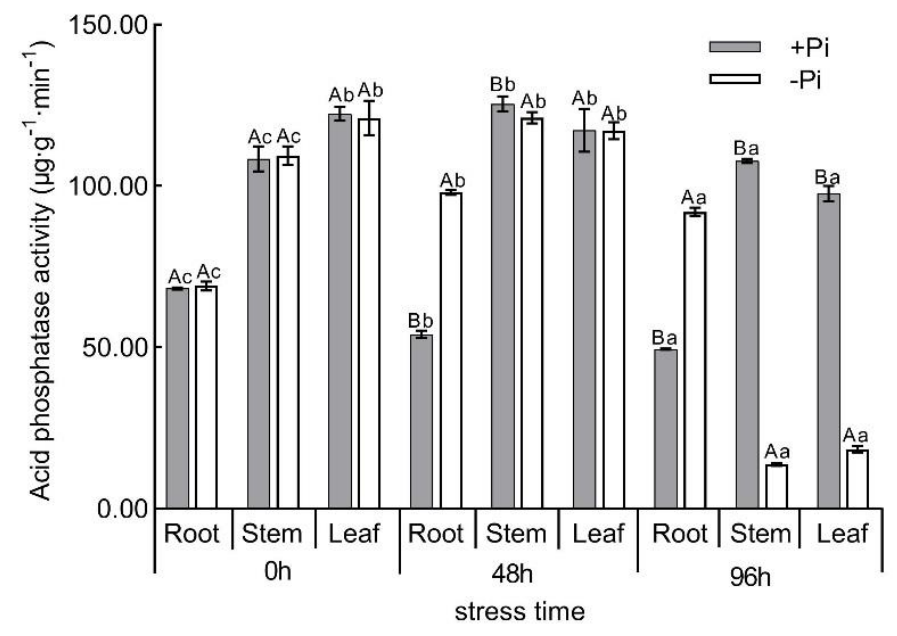

Figure 3. Acid phosphatase activity in organs of Moso bamboo at different stress times. Uppercase letters indicate a significant difference in acid phosphatase activity between the normal phosphorus group and the phosphorus deficiency group under the same treatment time. Lowercase letters indicate that acid phosphatase activity is significantly different in the same phosphorus treatment group under different treatment times. The mean values and SD (standard error of the mean) were obtained from three biological replicates, and a, b, c letters indicated significant differences $(p<0.05)$.

\section{Results}

\subsection{Physiological and Biochemical Analysis of Moso Bamboo under Low Phosphorus}

In order to study the effect of low phosphorus stress on the growth and development of Moso bamboo, the root morphology of Moso bamboo was analyzed after 20 days of hydroponic treatment with different phosphorus supplies. The study found that compared with normal phosphorus supply, low phosphorus stress inhibited the increase in root length, root volume, average root diameter and root surface area of Moso bamboo (Figure 1). However, low phosphorus stress promoted the increase of the number of Moso bamboo root hairs. It shows that low phosphorus will promote the changes of the root morphology of Moso bamboo, and it is speculated that this may be beneficial to improve the phosphorus absorption and utilization efficiency under low phosphorus stress. 
Upon further exploration of the effect of changes in the root morphology of Moso bamboo under low-phosphorus stress on the phosphorus content of plants, we found that, by measuring the soluble phosphorus content (Figure 2), the above-ground phosphorus content was significantly higher than that of the underground without phosphorus stress treatment. After 20 days of low-phosphorus stress, compared with normal phosphorussupplying plants, the phosphorus content in the underground part of Moso bamboo is significantly reduced, but the above-ground phosphorus content of the plant was higher than that of the underground. Presumably, this may be because the underground phosphorus from the underground part of the plant is decomposed by acid phosphatase and transported to the above-ground part of the plant to provide growth and development.

Under normal circumstances, low phosphorus stress can induce the increase in the plant acid phosphatase activity, and acid phosphatase promotes the absorption and utilization of phosphorus by plants [45]; therefore, we measured the activity of acid phosphatase in different organs of Moso bamboo after 0, 48 and $96 \mathrm{~h}$ low-phosphorus treatments (Figure 3). The results showed that at $0 \mathrm{~h}$, the acid phosphatase activity in leaves was the highest, followed by stems. The lowest was in roots, but there was no significant difference among different organs. After $48 \mathrm{~h}$ of normal phosphorus supply, the acid phosphatase activity of different organs was basically the same as that after $0 \mathrm{~h}$ treatment; however, under the induction of low phosphorus stress, the acid phosphatase activity of roots increased significantly, while the acid phosphatase activity of stems and leaves did not change significantly. After $96 \mathrm{~h}$ of normal phosphorus supply, the acid phosphatase activity in the stem was the highest, while the root was the lowest. Interestingly, we found that the acid phosphatase activity in the roots of Moso bamboo was significantly increased under low phosphorus stress compared with the normal phosphorus supply control group, but the acid phosphatase activity in the leaves and stems was much lower than the control group.

\subsection{Genome-Wide Characterization of PAP Genes in Moso Bamboo}

PAPs, as a kind of acid phosphatase, are involved in regulating phosphorus absorption and transportation in plants [17]. Combining with the results of low phosphorus stress inhibiting the growth of Moso bamboo roots, promoting the increase of root acid phosphatase activity and reducing the soluble phosphorus content, we speculate that PAP genes also play an important role in bamboo; therefore, the purple acid phosphatase gene family of Moso bamboo was analyzed. According to the chromosome position, 17 PAP genes (PePAP) were identified from Moso bamboo and named PePAP1-PePAP17. The protein sequences of the PePAP genes are listed in Table S2. Table 1 lists the detailed information of these PePAP genes, including the length of the CDS, the size of the amino acids, the molecular weight of proteins, the location of genes on the chromosome, isoelectric point (PI) and subcellular localization prediction.

The length of the CDS of PePAP1-PePAP17 is 1329-2322 bp, and the length of the protein is $443-773$ aa. PePAP15 is the smallest PAP protein with 443 amino acids, and the largest protein is PePAP13 with 773 amino acids. The predicted molecular weight of the 17 PePAP proteins is between 48.00 (PePAP15) and $56.4 \mathrm{kDa}$ (PePAP13), with an average size of $62.10 \mathrm{kDa}$. The theoretical isoelectric points of the $17 \mathrm{PePAP}$ proteins are 5.16-7.76; the average predicted isoelectric point of the encoded protein is 6.43, which are all lower than 10.0, and the smallest protein (PePAP16) is 5.16. According to the prediction of the signal peptide, there are four Moso bamboo PAP proteins (PePAP1, PePAP2, PePAP8 and PePAP14) located in the nucleus, and seven PAP proteins (PePAP3, PePAP6, PePAP7, PePAP12, PePAP15, PePAP16 and PePAP17) simultaneously located in the nucleus and cell wall. It is worth noting that PePAP13 is located in both the chloroplast and cell nucleus, indicating to a certain extent that it may be related to photosynthesis. In addition, there are five PAP proteins (PePAP4, PePAP5, PePAP9, PePAP10 and PePAP11) located outside the cell, indicating that they may be secreted proteins. The detailed information is summarized in Table 1. 
Table 1. Characteristics of the purple acid phosphatase (PAP) genes in Moso bamboo.

\begin{tabular}{|c|c|c|c|c|c|c|c|c|}
\hline Name & Gene ID & Location & $\begin{array}{c}\text { ORF } \\
\text { Length } \\
\text { (bp) }\end{array}$ & $\begin{array}{l}\text { Size } \\
\text { (aa) }\end{array}$ & $\begin{array}{c}\text { MW } \\
(\mathbf{k D a})\end{array}$ & PI & $\begin{array}{c}\text { Predicted } \\
\text { Location(s) }\end{array}$ & $\begin{array}{l}\text { Phylogenetic } \\
\text { Group }\end{array}$ \\
\hline PePAP1 & PH02Gene03873.t1 & $\begin{array}{c}\text { 64125824-64134183 } \\
\text { (+strand) }\end{array}$ & 1887 & 628 & 68.89 & 6.63 & Nucleus & IV \\
\hline PePAP2 & PH02Gene06180.t2 & $\begin{array}{c}\text { 41970818-41973326 } \\
\text { (+strand) }\end{array}$ & 1638 & 545 & 60.43 & 6.76 & Nucleus & II \\
\hline РePAP3 & PH02Gene08370.t1 & $\begin{array}{c}100943784-100947526 \\
(- \text { strand })\end{array}$ & 1626 & 541 & 60.50 & 5.72 & $\begin{array}{l}\text { Cell wall, } \\
\text { Nucleus }\end{array}$ & I \\
\hline PePAP4 & PH02Gene13885.t1 & $\begin{array}{c}\text { 36547136-36557904 } \\
\text { (+strand) }\end{array}$ & 1431 & 476 & 55.33 & 7.04 & Extracellular & III \\
\hline PePAP5 & PH02Gene17860.t1 & $\begin{array}{c}\text { 61935055-61946690 } \\
\text { (-strand) }\end{array}$ & 1404 & 467 & 53.10 & 6.85 & Extracellular & III \\
\hline PePAP6 & PH02Gene18076.t1 & $\begin{array}{c}\text { 61150761-61154907 } \\
\text { (+strand) }\end{array}$ & 1968 & 655 & 74.15 & 6.03 & $\begin{array}{l}\text { Cell wall, } \\
\text { Nucleus }\end{array}$ & IV \\
\hline PePAP7 & PH02Gene19604.t1 & $\begin{array}{c}\text { 10147974-10154225 } \\
\text { (+strand) }\end{array}$ & 1854 & 617 & 68.93 & 6.55 & $\begin{array}{l}\text { Cell wall, } \\
\text { Nucleus }\end{array}$ & IV \\
\hline РePAP8 & PH02Gene21481.t4 & $\begin{array}{c}86205603-86209154 \\
(- \text { strand })\end{array}$ & 1863 & 620 & 68.38 & 6.26 & Nucleus & I \\
\hline PePAPG & PH02Gene27343.t1 & $\begin{array}{l}\text { 49726678-49738431 } \\
\text { (-strand) }\end{array}$ & 1383 & 460 & 52.43 & 6.51 & Extracellular & III \\
\hline PePAP10 & PH02Gene27344.t1 & $\begin{array}{l}\text { 49720108-49723291 } \\
\text { (-strand) }\end{array}$ & 1383 & 460 & 52.48 & 6.08 & Extracellular & III \\
\hline РePAP11 & PH02Gene27346.t1 & $\begin{array}{l}49685388-49688197 \\
(- \text { strand })\end{array}$ & 1452 & 483 & 54.56 & 6.38 & Extracellular & III \\
\hline PePAP12 & PH02Gene28188.t1 & $\begin{array}{c}24090526-24094241 \\
(- \text { strand })\end{array}$ & 1953 & 650 & 73.66 & 6.79 & $\begin{array}{l}\text { Cell wall, } \\
\text { Nucleus }\end{array}$ & IV \\
\hline PePAP13 & PH02Gene29678.t1 & $\begin{array}{c}\text { 19498663-19503808 } \\
\text { (-strand) }\end{array}$ & 2322 & 773 & 87.83 & 6.59 & $\begin{array}{l}\text { Chloroplast, } \\
\text { Nucleus }\end{array}$ & II \\
\hline PePAP14 & PH02Gene33883.t3 & $\begin{array}{c}\text { 32855977-32859136 } \\
(- \text { strand })\end{array}$ & 1809 & 602 & 67.37 & 7.76 & Nucleus & II \\
\hline PePAP15 & PH02Gene33886.t1 & $\begin{array}{l}\text { 32922514-32926606 } \\
\text { (+strand) }\end{array}$ & 1329 & 443 & 48.00 & 5.62 & $\begin{array}{l}\text { Cell wall, } \\
\text { Nucleus }\end{array}$ & II \\
\hline PePAP16 & PH02Gene42583.t1 & $\begin{array}{l}\text { 4108516-4112174 } \\
\text { (+strand) }\end{array}$ & 1374 & 457 & 50.12 & 5.16 & $\begin{array}{l}\text { Cell wall, } \\
\text { Nucleus }\end{array}$ & II \\
\hline PePAP17 & PH02Gene48530.t1 & $\begin{array}{c}5657804-5664682 \\
(- \text { strand })\end{array}$ & 1587 & 528 & 59.56 & 6.52 & $\begin{array}{l}\text { Cell wall, } \\
\text { Nucleus }\end{array}$ & II \\
\hline
\end{tabular}

ORF: open reading frame, bp: base pair, aa: amino acids, MW: molecular weight, kDa: kilodalton, PI: isoelectric point.

\subsection{Phylogenetic Analysis of Bamboo PAP Genes}

In order to further explore the possible role of PAPs in the evolution of Moso bamboo, a phylogenetic tree was constructed to 72 PAPs sequences from three species ( $A$. thaliana, rice and Moso bamboo) was performed using the neighbor-joining method (NJ) method. The phylogenetic results show that these PAPs can be divided into six categories (group I-VI, Figure 4). Groups III and IV each contain 18 members. In group III, five Moso bamboo PAPs (PePAP4, PePAP5, PePAP9, PePAP10 and PePAP11) are clustered with five rice and eight $A$. thaliana PAPs (Figure 4). Among the 18 members in group IV, four are Moso bamboo PAPs (PePAP1, $-6,-7$ and -12 ), nine are rice and five are $A$. thaliana PAP genes (Figure 4). Interestingly, six Moso bamboo (PePAP2, PePAP13, PePAP14, PePAP15, PePAP16 and PePAP17) and five rice PAP genes were found in Group II of the second largest group, but only identified in $A$. thaliana three $P A P$ gene within the group (Figure 4 ). There are two Moso bamboo PAP genes (PePAP3 and PePAP8) among the seven members of group I. It is particularly noteworthy that group $\mathrm{V}$ seems to be specific to dicotyledonous plants, with only four PAP genes in A. thaliana. The genes from group VI were eliminated in Moso bamboo or, more precisely, in Moso bamboo ancestors, but not in rice (Figure 4), which indicates that, compared to $A$. thaliana and rice, Moso bamboo may lack the function of PAP genes in groups $\mathrm{V}$ and VI. 


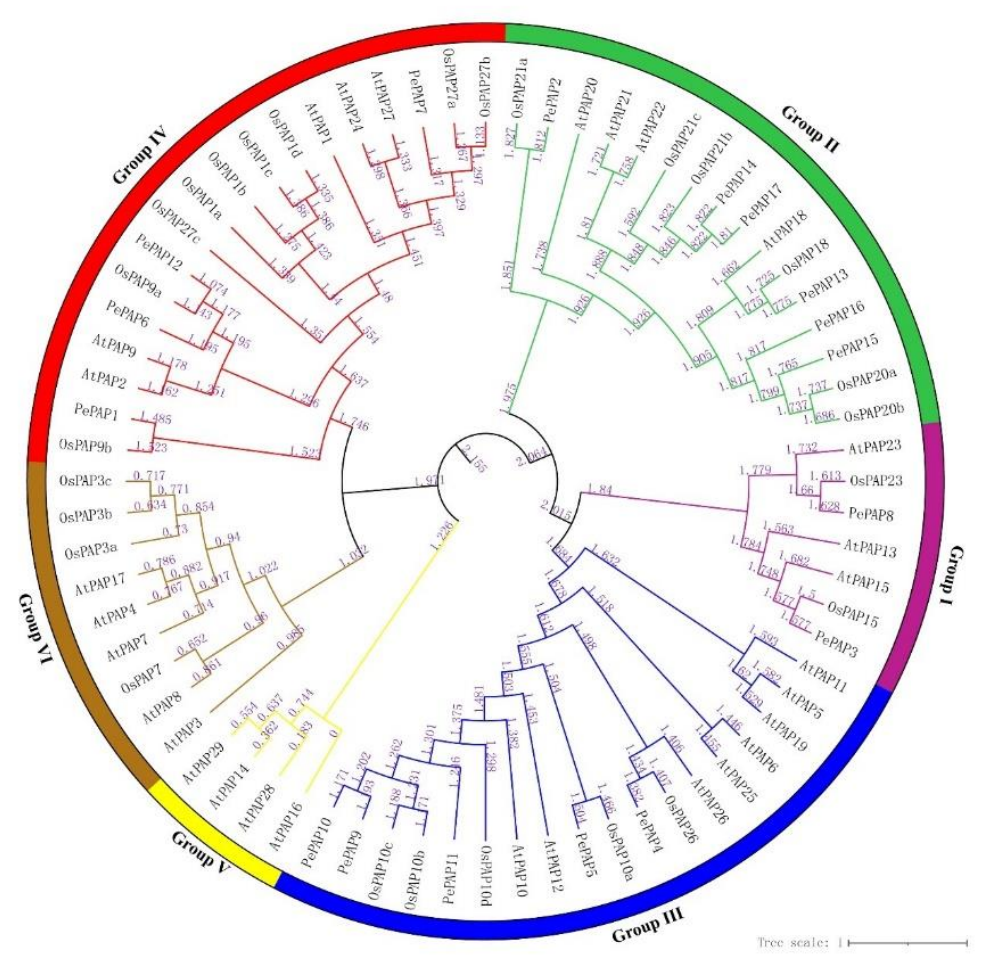

Figure 4. Phylogenetic analysis of purple acid phosphatase (PAP) protein (PePAP) in bamboo, rice and $A$. thaliana. The phylogenetic tree was made based on the amino acid sequences using MEGA7.0 by the neighbor-joining method with 1000 bootstrap replicates. The tree shows six major phylogenetic groups (I to VI) indicated by different colors. The gene names of $A$. thaliana, rice and bamboo PAP genes were begun with "At", "Os", and "Pe", respectively.

\subsection{The Conservation of PAP Motifs and Structure In Moso Bamboo PAP Proteins}

To further investigate and characterize sequence conservation in the Moso bamboo PAP proteins, multiple sequence alignments were performed using the predicted 17 Moso bamboo PePAP amino acid sequences (Figure 5). The 17 PAP proteins all showed conserved blocks with metal-specific motifs. The number of conserved motifs in PePAP proteins is also different. Except for PePAP6, and PePAP12, the other PePAP proteins contain five conserved amino acids. It is worth noting that the conserved motifs of PePAP protein all contain the invariant residues "YER", which are adjacent to the conserved metal-binding motif "GHX ${ }^{\mathrm{H}}$ ". This is similar to the conservative motif of the PAP protein of the tea plant but different from $A$. thaliana and rice. The invariant motif "YER" only exists only in some members of the PAP family of $A$. thaliana and rice [46]. The results showed that most bamboo PePAP proteins have highly conserved PAP motifs.

In order to further reveal the diversity of PePAP protein in Moso bamboo, the gene structure of PePAP was predicted through the GSDS database. Research shows that the total number of exons of each group of PePAP genes was calculated. Except for the second group of PePAP15 and PePAP16 genes, which have only three exons, the fourth group of PePAP6 and PePAP12 have two exons, and the remaining PePAP genes have 5 to 13 exons (Figure 6A).

Presumed conserved functional domains and motifs were predicted in the National Center for Biotechnology Information (NCBI) conservated domain database and MEME (Multiple EM for Motif Elicitation) programs. As expected, all PePAP proteins contain at least one PAP domain (PLN02533 superfamily, MPP_PAPs, fn3_PAP superfamily, Pur_ac_phosph_N and fn3_PAP, Figure 6B,C). 
GDXX $\underline{Y}$

\begin{tabular}{|c|c|}
\hline & \\
\hline EPAP14 & ...LGTGWTASTISHIGGS.. \\
\hline EAP15 & .. NPSREFSFRTPF. . . . SSLPFNFVVZGE. \\
\hline PAP7 & NEYMNYQPGSLNTTDTLIKDLD . ....NIDIVFHIE \\
\hline PePAP6 & NTYIRTCEESISTVKWILRDIQALGDKFAFISHIGL \\
\hline PePAP12 & NTYFRTPYESISTVKWIFRDLEALGDKAAFISHIGLI \\
\hline PEPAP4 & ...LGCTFNSLSTLCHYERS........GGQTVLFYGLISYDDRYQHND. \\
\hline PePAP9 & ...LGTTFDSNSTISHYEAN $\ldots . . .$. GGDAVI FMGLISYADHYPLHD. \\
\hline PEPAPIO & ..LGCTFDSNSTISHYEAN........GGDAVLFMGLI \\
\hline PePAPII & 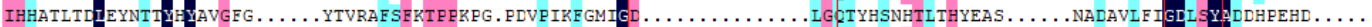 \\
\hline PePAP17 & ... LGQTGWTASTLSHIGGA $\ldots \ldots$ DYDMLILAG \\
\hline PePAP8 & ....LGETGNSTSTIDHLARN . ......GPSLIVIVGDMTYMNOYRTTGGRGVP \\
\hline PePAP16 & IHDAVIGELCPSMTYYYRCSS $\ldots \ldots \ldots$ DPSREFSFRTPE $\ldots \ldots$ STLPFNFVVYGD \\
\hline PEPAPI & SDS $\ldots .$. VGWSDTIKFKTETAAG . ADELSFVIYGLMGKAPLDPSVEHYIQPG \\
\hline PePAP5 & 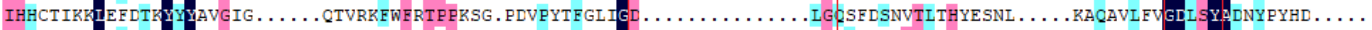 \\
\hline PEPAP3 & ..PGETYNTTSTIDHMASN.......QPDLILLVG \\
\hline PEPAP13 & $\ldots$ LGCTSWTISTLNHIRQC.......EHDMLILEGL \\
\hline PePAP2 & $\ldots \ldots$. RVGDEFTLKTPF.....AALPIELALVGI \\
\hline Consensus & 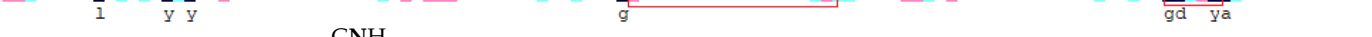 \\
\hline EPAP14 & WISFGRLVQPLASAR FWMVTEGNEEIET. . \\
\hline PePAP15 & $\ldots$ FKAYNARWRM YYDAGA ......SESGSNLYYSFDVAGGAVHVIMIGSYTDF \\
\hline PEPAP7 & CETCQVEPITSRVPYMIASGNHERDWFNSGSFYNGKDSGG .... \\
\hline PePAP6 & 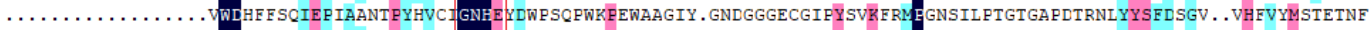 \\
\hline PePAP12 & 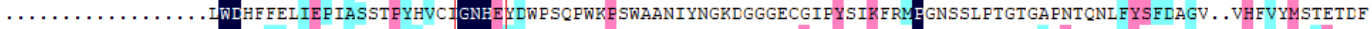 \\
\hline PEPAP4 & ILSWGRLVERSAAYQPWIWNZ GNHEIEY $\ldots \ldots$ RPDLGETST $\ldots \ldots \ldots \ldots$ FKPYKHRYTIEYLA $\ldots \ldots \ldots$ SKSSSPMWYAVK \\
\hline PEPAP9 & .. FRPFTHRYPTEFRT $\ldots . . .$. AGSTEPFWYSVKMAS...AHIVVIASYSAY \\
\hline PePAP & WLTWARFAERSVAYQPWIWVAGNHELDF.....SEEIGETTP.. \\
\hline PePAP11 & 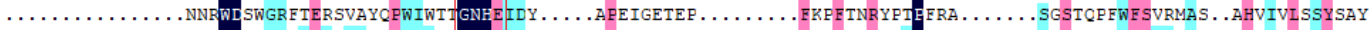 \\
\hline PEPAP17 & $\ldots$ FVAYNARWRMEHEE $\ldots \ldots \ldots$ SGSASNLYYSF DAAGGAVHVVMI GSYTGF \\
\hline PEPAPB & NLGWGRFMEPLASKIPTMVIRGNHEIE....... FCGHGGAV... \\
\hline PEPAP16 & ....FRAYNARWRM EYDAGA $\ldots .$. . SESGSNLYYSFDVAGGAVHVIMIGSYTDF \\
\hline & IFFLHLITPLASQVSYMTA GNHERDYAASGSVYVTPDSGG $\ldots$ \\
\hline PePAP5 & DTWARFVERNVAYCPWIWTA GNHEIDF $\ldots \ldots$ AFELGETRP $\ldots \ldots \ldots$ FRPYSHRYPIEYKA $\ldots \ldots \ldots$ SGSTAPYWYSIR \\
\hline PePAP3 & 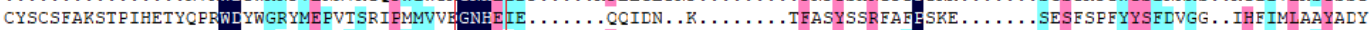 \\
\hline PEPAP13 & 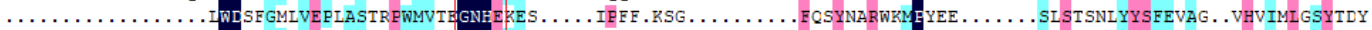 \\
\hline PePAP2 & 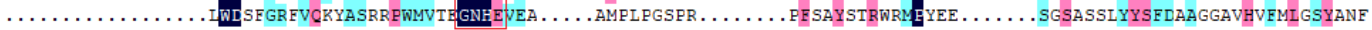 \\
\hline Consensus & $\mathrm{VXX} \underline{\underline{\mathrm{w}}} \quad \mathrm{G} \quad \underline{\mathrm{H} X}$ \\
\hline & TPWLVVIIFAEWYNTNC . . AHCGEG . . . . ERMRRAMESLIYEARVIVV \\
\hline EPAP15 & AHCGDG.... DAMRAAMEALIYGAR \\
\hline EPAP7 & RTCPVYEEQCVSSEKSHYSG. \\
\hline EPAP6 & RTPFVYECGH REMYTSSNEARDFAMR $\ldots .$. QCMLCHLEPLIVTYMVTLALWG \\
\hline PEPAP12 & RTPEIVECGH REMYTSSNEVRDTAHR ....ECMIQHLEPLFVRHIVTLALWG \\
\hline ePAP4 & SYRISNVNYNITSGNRYP.. \\
\hline PePAP9 & SNVEYNIVNGKSTP.. \\
\hline PEPAP & SRRE SNVEYNIVNGKSTP.. \\
\hline PAP. & 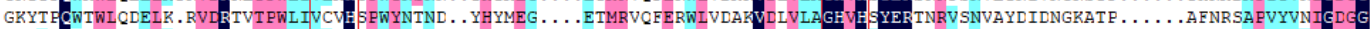 \\
\hline PePAP17 & RTPWLVVLIHAPWYNTNQ . . AHQGEG . . . ERMRKAMERLIYYEARVIVVFAGH \\
\hline PEPAP8 & SEWYNSYS . .SHYQEF . . . ECMMRQEMEGLIYR: \\
\hline & ..DGMRAAMEALIYGARV \\
\hline PePAP1 & RTPWVIF IGHREMYSSNVG. ILPNVD. \\
\hline PePAP5 & ETTPWL IVL M APWYNSYN.. YHYMEG $\ldots \ldots$ ETMRVMYY PWFVKHKV \\
\hline PEPAP3 & VTPWL IA GWHARWYSSYR . . AHYREA $\ldots$. ECMRVEMEELIYN \\
\hline PEPAP13 & NPWYNSNW . . AHCGEG . . . . DS! \\
\hline & \\
\hline & \\
\hline
\end{tabular}

Figure 5. The alignment of the PePAP protein family in Moso bamboo. Alignment of the domain sequences. The conservative regions are boxed.
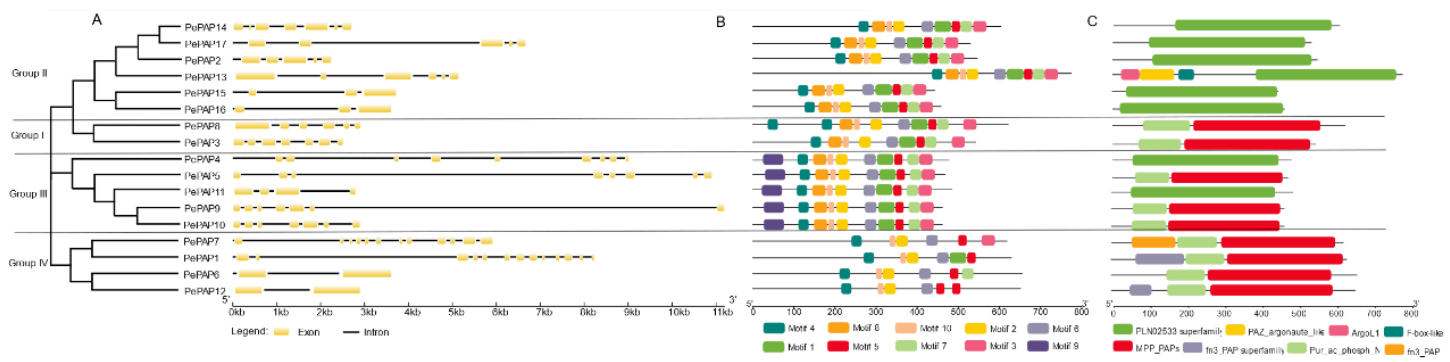

Figure 6. Schematic representation of gene structure, motifs and conserved domains of PAP proteins. (A) Exon/intron structures of PePAP genes. Phylogenetic tree construction of the PePAP proteins based on the amino acid sequences using MEGA7.0. The position of the sequence and the size of exons or introns can be estimated by the scale at the bottom. (B) Distribution of conserved motifs in PePAP proteins identified by motif-based sequence analysis tools (MEME). (C) Conserved domains of PePAP proteins. Each color represents a different domain, motif and structure of the protein.

\subsection{Characterization of Cis-Acting Elements in the Promoter Regions of PePAPS}

In order to further the possible regulatory mechanism of the PePAP gene, the ciselements in the promoter region of the PePAP gene were analyzed using the PlantCARE database. A series of hormone-related (such as abscisic acid, auxin, gibberellin, jasmonic acid, salicylic acid and flavonoids), developmental related (such as light response, circadian 
rhythm control, meristem expression, endosperm expression, zein Protein, root-specific expression and cell cycle regulation), stress-related (such as low-temperature, anaerobic induction, hypoxia, defense, stress and wound response) and cis-acting elements were identified in Figure 7. In hormone cis-acting elements, $64.71 \%$ of PePAPs (11 genes) have jasmonic acid response elements, which are the most abundant cis-acting elements, with a number reaching 22. In addition, there is 14 abscisic acid responsiveness (ABRE), 4 auxin responsiveness (AuxRR-core, TGA-box, TGA-box), 11 gibberellin responsiveness (GAREmotif, $P$-box, TATC-box), 7 salicylic acid reactivity (TCA-element), 1 flavonoid biosynthesis reactivity (MBSI) and 5 zein metabolism regulation (02-site). Among the cis-acting elements related to development, 78 cis-acting elements (AAAC-motif, ACA-motif, ACE, AE-box, AT1-motif, ATC-motif, ATCT-motif, Box4, BoxII, CCAAT-box, chs- CMA1a, chs-CMA2a, G-box, Gap-box, GATA-motif, GT1-motif, GTGGC-motif, I-box, L-box, LAMP-element, Sp1, TCCC-motif and TCT-motif) are related to the light response of plants. In addition, there are 12 meristem expression elements (CAT-box), 1 circadian rhythm cis-acting element, 3 endosperm-specific expression elements (GCN4_motif), 1 root-specific element (motif I) and 1 Cell cycle control element (MSA-like). In addition, many cis-acting elements were detected to be related to low-temperature tolerance (LTR), defense and stress (TC-rich repeats, WUN-motif) and abiotic resistance (ARE and GC-motif). This result indicates that PePAPs may participate in the process of low phosphorus stress and play an important role in biological growth and development.

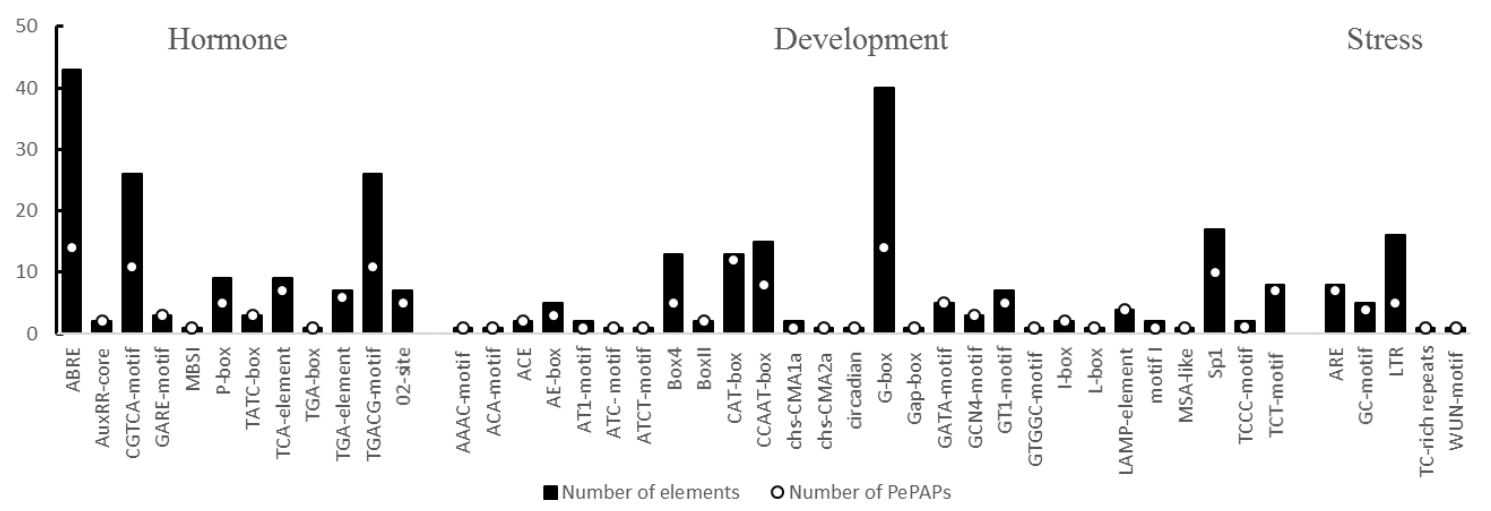

Figure 7. Various cis-acting elements in the promoter of $P e P A P$ genes. The white circles indicate how many $P e P A P$ genes have corresponding homeopathic elements.

\subsection{Expression Pattern of PePAP Genes in Moso Bamboo under Low Phosphorus Stress}

The transcriptional expression pattern of the PePAP gene of bamboo seedlings at 0 and $96 \mathrm{~h}$ after Pi starvation was analyzed by qPCR (Figure 8). The results showed that PePAP genes are also ubiquitously expressed in Moso bamboo under a normal phosphorus supply treatment, but the expression patterns of some genes are organ-specific. PePAP1, PePAP3, PePAP7, PePAP12 and PePAP14 genes were expressed on higher levels in leaves than in roots or stem., and PePAP4, 6, 8, 13 and 15 genes are expressed on a higher level in roots than in leaves or stem of Moso bamboo. After the induction of low phosphorus stress, the expression of PePAP1, PePAP3, PePAP7, PePAP11, PePAP12, PePAP15 and PePAP17 in the leaves of Moso bamboo was significantly increased. The expression of PePAP2, PePAP4, PePAP5, PePAP6, PePAP8, PePAP9, PePAP13, PePAP14 and PePAP16 genes showed an increasing trend in the stem. However, the expression of PePAP genes in roots did not change much; only PePAP12 and PePAP16 showed increased expression. Interestingly, the expression level of the PePAP10 gene in roots, stems and leaves was significantly increased. 

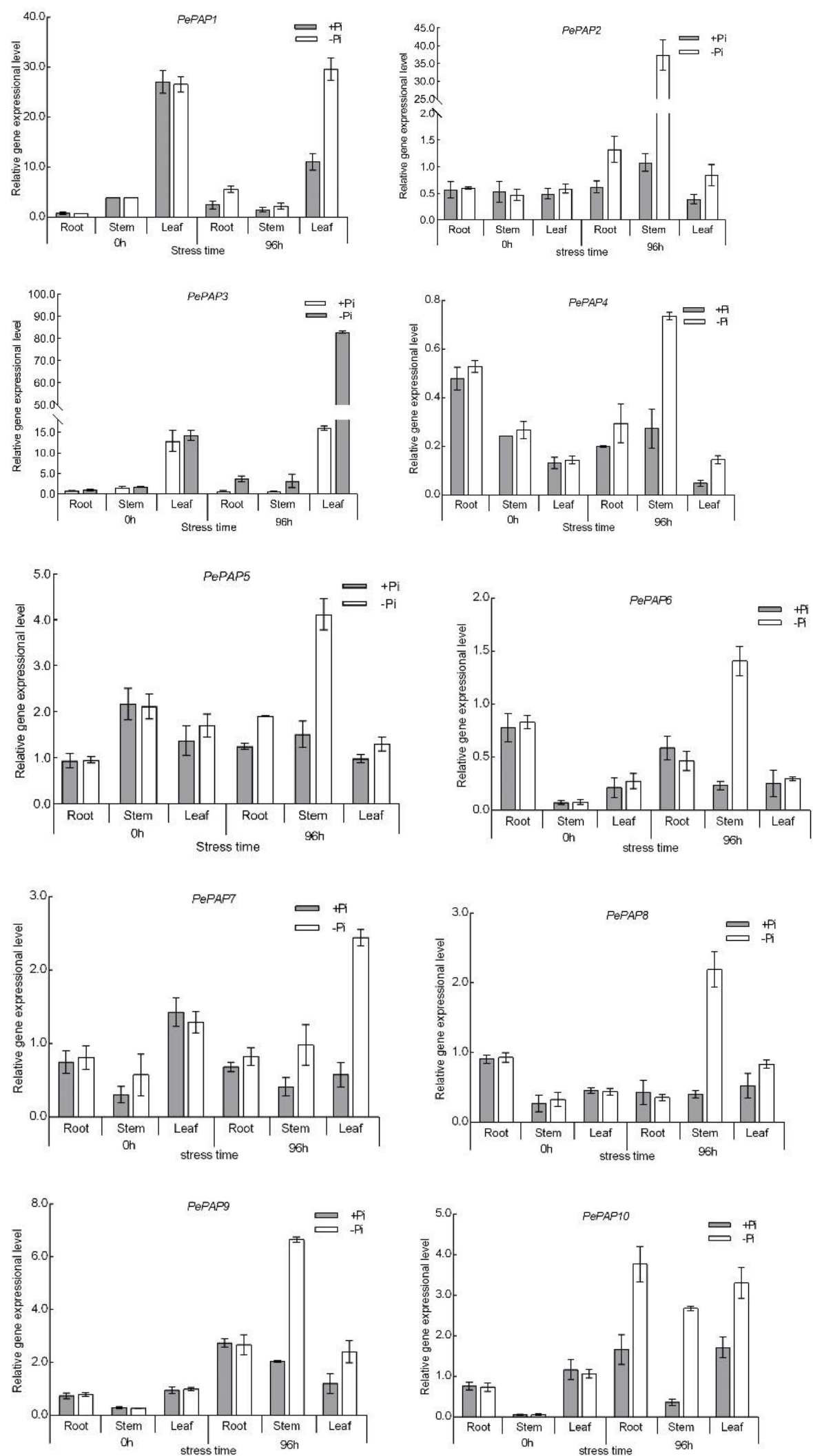

Figure 8. Cont. 

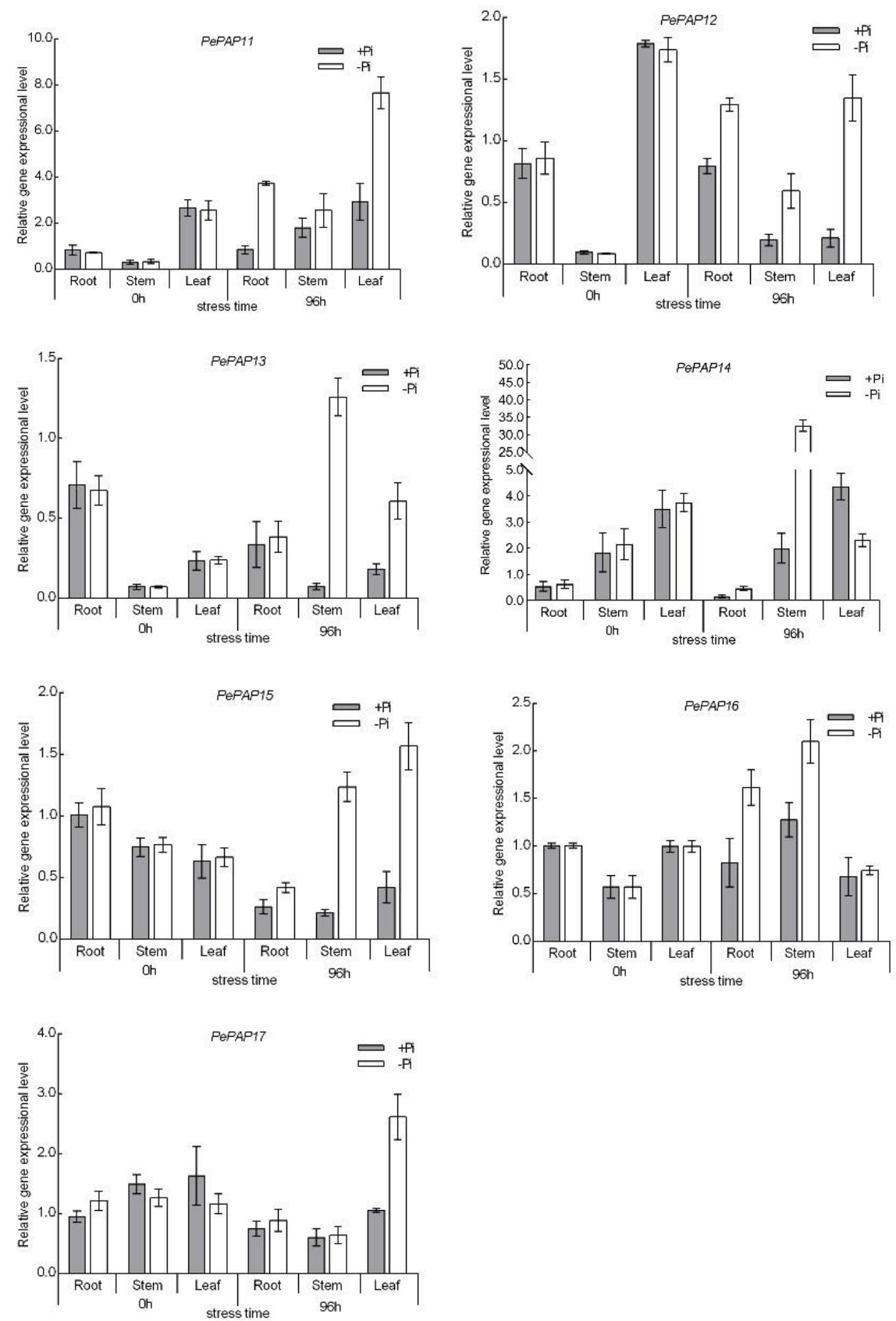

Figure 8. Expression analysis of Moso bamboo PAP genes in different organs, using qRT-PCR.

\section{Discussion}

In the fast-growing Moso bamboo plantation management under the multi-generation continuous planting management model, one of the key limiting factors for yield increase and sustainable management is the lack of soil phosphorus nutrition. In our research, we found that Moso bamboo under low-phosphorus stress exhibits low-phosphorus adaptation characteristics, such as root morphology changes, phosphorus remobilization and increased acid phosphatase activity. Studies have shown that enhancing the secretion of purple acid phosphatase is a unique adaptation strategy for plants to grow under low phosphorus stress and plays an important role in phosphorus metabolism [13,46,47]. Purple phosphatase is a special acid phosphatase with wide substrate specificity [48]. Proteins, such as AtPAP15 [49], GmPAP4 [47], TapAPhyb1 [50] and CaPAP7 [51], only catalyze the decomposition of phytic acid and are substrate specificity, whereas most 
PAP proteins can hydrolyze ATP, phosphoenolpyruvate and phosphorylated proteins and other types of phosphate monoesters. The hydrolytic activity is called nonspecific PAP. It plays an important role in maintaining phosphorus homeostasis by hydrolyzing various organophosphorus compounds under weak acid conditions [4,52]. This inspired us to analyze the PAP gene family and their expression patterns of Moso bamboo, hoping to provide references for revealing the low-phosphorus adaptation mechanism of Moso bamboo and provide key candidate genes for the genetic engineering supported breeding of Moso bamboo. To achieve this, we first studied the effects of low phosphorus stress on the root morphology, soluble phosphorus content and acid phosphatase activity of Moso bamboo and then analyzed the protein physicochemical properties of the closely related members of the purple acid phosphatase gene family. We conducted a phylogenetic analysis to determine the evolutionary relationship between PAP genes. Then, we analyzed the gene expression of all identified bamboo PAP genes in different organs and their response to phosphorus starvation treatment.

The adaptability of plants to low phosphorus can be divided into two types: enhanced phosphorus absorption and phosphorus utilization efficiency. These two methods are the basis for plants to adapt to low phosphorus morphological changes. Plants suffering from low phosphorus stress will increase the surface area of roots, thereby promoting phosphorus absorption, including morphological adaptations: the increase in the root-toshoot ratio [53]. The main morphological response of plants in response to low phosphorus stress is to reduce shoot growth, reduce the plant's overall demand for phosphorus. When plants respond to low-phosphorus stress, in addition to restricting the growth of the aboveground parts to reduce the demand for phosphorus [54-56], the root morphology and structure of the root system will also be greatly changed. The main root grows towards lateral roots and row roots [57], increasing the length and density of root hairs [58]. Some species form highly aggregated lateral roots, or row roots, increasing the root surface area. Under low phosphorus stress, the root hair density of $A$. thaliana seedlings has increased five-fold, and the altered root morphology accounts for up to $70 \%$ of the root absorption area [59]. The growth of OsPAP10c overexpressing plants was inhibited in pot or field trials [60]. Similarly, the overexpressing of GmPAP1 and GmPAP21 in soybean roots also resulted in lower fresh weight than the control line under sufficient Pi conditions [38,61]. Similarly, in our study, under the low phosphorus stress, compared with the normal phosphorus supply, the increase in root length, the increase in root volume, the increase in average root diameter and the increase in root surface area of Moso bamboo were significantly reduced (Figure 1). We speculate that this may be related to the increased expression of PePAP genes in the roots of Moso bamboo under low phosphorus stress. To a certain extent, it shows that low phosphorus promotes the change of root structure and the enhancement of root acid phosphatase activity. Although the Moso bamboo will produce a low-phosphorus tolerance reaction, the effect of low-phosphorus conditions on it cannot be ignored. Low-phosphorus stress reduces the phosphorus content of Moso bamboo and underground. Overall, low phosphorus has a negative regulatory effect on the growth and development of Moso bamboo.

Plant PAPs are closely related to the decomposition and absorption of soil organic phosphorus and the reuse of phosphorus in plants. Many plant-derived PAPs have acid phosphatase activity, which can transform organic phosphorus in and out of plants into the phosphorus that is accessible for the plant for plants to absorb and utilize [20]. It is reported that the activity of acid phosphatase in rice can be significantly enhanced under low phosphorus induction, which can promote the absorption and utilization of phosphorus and then affect the plant biomass [12]. Interestingly, in our study, low phosphorus also induced the increase in acid phosphatase activity in the root, stem and leaf organs of Moso bamboo, but with the increase in low phosphorus treatment time, the acid phosphatase activity in stems and leaves decreased significantly. Moreover, the acid phosphatase activity in the roots of Moso bamboo was not significantly reduced (Figure 3). By determining the phosphorus content of Moso bamboo, it was found that after $20 \mathrm{~d}$ of low-phosphorus 
treatment, the phosphorus content in the underground part of bamboo was significantly lower than that in the above-ground part (Figure 2). We speculate that the acid phosphatase in the underground organs of Moso bamboo decomposes organic phosphorus, promotes the absorption of inorganic phosphorus and is then transported to the above-ground parts. In addition, this may also be related to root cells secreting acid phosphatase to the surface of the root system, thereby promoting the absorption of phosphorus in the culture medium. As the phosphorus treatment time increases, the concentration of phosphorus in the above-ground part of the plant increases, which in turn affects the acid phosphatase in above-ground parts of plants. Acid phosphatase activity is negatively regulated. Then, we measured the phosphorus content in Moso bamboo and found that, as we had guessed, the phosphorus content in the underground dropped significantly after low phosphorus stress.

We have identified 17 PAP members in Moso bamboo, which is similar to the previously reported number of PAPs in chickpeas, tomatoes, and Jatropha curcas [33,52,55]. In view of the huge differences in genome size between these plant species, the proteins encoded by the PAP genes of the same species have greater conservation [56]. In addition, groups I to IV from Moso bamboo showed highly evolutionary conservation compared to A. thaliana and rice. Phylogenetic analysis of identified PAP members showed that they were different from $A$. thaliana and rice homologs; PAP of Moso bamboo formed four main groups (I, II, III and IV); A. thaliana PAP formed six groups, whereas rice formed five groups (Figure 4). This is in agreement with the fact that the evolution of genes differs in different plant species. The 17 Moso bamboo PAP proteins all have conserved regions of metal-specific motifs (Figure 5). Except for PePAP2 and PePAP12 lacking one metal ion-binding amino acid residue, the remaining 15 PePAP proteins preserve all seven amino acids involved in binding metal ions. In our study, the PePAP proteins are highly conserved in Moso bamboo; however, the number of conserved motifs in PePAP protein is different. The highly conserved motifs in PePAPs were identified by the MEME tool (Figure 6B). PePAP in the same subgroup has similar motifs, indicating that these motifs are indispensable for the specific functions of the subgroup. However, the PePAP8 structure in the group I subgroup has one more motif-4 motif than PePAP3, which indicates that PePAP8 might be higher than PePAP3 in terms of specific functions with motif-4 motifs. Similarly, the JcrPAP12 gene in Jatropha has a complete motif, so it appears to be specifically induced to be expressed in the stem under low phosphorus stress [37].

The cis-acting elements in gene promoters determine gene expression patterns through the binding sites of transcription factors [52]; therefore, by identifying the cis-elements in its promoter, the function of PePAP can be predicted. Previous studies have found that GmPAP3 can reduce the damage caused by salt and peroxide stress by inhibiting the accumulation of reactive oxygen species (ROS) [62,63]. AtPAP15 releases inositol and inorganic phosphorus by hydrolyzing phytate, and inositol participates in the ascorbic acid synthesis pathway, thereby regulating the stress adaptability of plants [31]. In our study, a series of hormone, developmental and stress-related cis-acting elements were tested for promoter PePAP (Figure 4). Among hormones, the ABRE cis-acting element is the largest number and controls the synthesis of abscisic acid. As we all know, abscisic acid can participate in the regulation of plant resistance [46]. Among the stress-related cis-acting elements, the LTR cis-acting element has the largest number, which regulates the pathway of plant low-temperature tolerance. There are homeopathic elements (TC-rich repeats, WUN-motif, ARE and GC-motif) related to stress and abiotic resistance in the PePAP gene of Moso bamboo. It may be that some PePAP genes are abundantly expressed under low phosphorus key. Therefore, it can be speculated that under the regulation of cis-acting elements, PePAPs may participate in biotic and abiotic stress responses and plant growth and development.

A set of adaptive changes in morphology, physiology, biochemistry, etc., formed by plants under long-term adaptation to low-phosphorus growth environments are essentially the result of the coordinated expression of many low-phosphorus-responsive genes. Different plants have differences in the absorption, transportation and utilization efficiency of 
phosphorus. For phosphorus metabolism under low phosphorus stress, plants also show diversity in root morphology, acid phosphatase activity and phosphorus concentration. As a gene responding to low phosphorus stress, the PAP genes also showed differential expression in plants. González-Muñoz et al. [64] observed that the maize PAP gene is specifically expressed in nutrient and reproductive tissues, and the expression levels of each gene in the tissues were different. They believe that these expression differences are due to the functional differences in the rate of mRNA production during the evolution of the maize PAP gene family. Baskar et al. [37] also reported that most of the JcrPAP genes of Jatropha were only expressed only in root organs, and no correlation between gene expression and phylogenetic analysis was found. At the same time, there are similar reports in tomatoes [52]. Similarly, in this study, most PePAP genes showed high expression in root and leaf organs, while their expression in stem organs was relatively low. In addition, PePAP1, PePAP2, PePAP11 and PePAP14 are highly expressed in the roots, stems and leaves of Moso bamboo, indicating that they also have functions other than phosphorus metabolism (Figure 8). According to our results, some PAP genes in rice, soybean, corn and tomato are induced by low phosphorus conditions [52,64,65]; however, in our study, most PePAP genes showed high expression in the stem organs of Moso bamboo treated with low phosphorus. Some PAP genes of Moso bamboo were specifically induced in the root and leaf organs treated with phosphorus. This indicates that there can be tissue differences in $P A P$ gene expression in different plant species. In addition, the expression levels of PePAP10, PePAP12 and PePAP16 in the roots of plants treated with low phosphorus were significantly increased (Figure 8), which is basically consistent with the expression trend of acid phosphatase activity. We speculate that these three genes may regulate the surface acidity of the Moso bamboo root. The activity of phosphatase, in turn, controls the distribution of soluble phosphorus in different organs. In particular, the expression of the PePAP10 gene in roots increased significantly under low-phosphorus treatment, which is consistent with the increase in rice OsPAP10c expression after low-phosphorus induction [12]. Interestingly, PePAP10 and OsPAP10c are both in Group III and in the same clade. We speculate that they may be orthologous genes, so they have great similarities in gene function. Compared with the control, the expression levels of most genes in the Moso bamboo treated with low phosphorus were higher, indicating that the PePAP gene may play a role in the collection and recycling of phosphorus. This further shows that the functions of the plant $P A P$ genes are diverse and complex.

\section{Conclusions}

In Moso bamboo, low phosphorus stress induces the increase in acid phosphatase activity in the root system and the transfer of soluble phosphorus from underground to the shoot, but the growth and development of the root system are negatively regulated. In addition, we identified 17 PAP genes in Moso bamboo. Phylogenetic analysis shows that the PePAP family can be divided into four subgroups. The gene structure and conserved domains of each subgroup are similar to the homologous genes of $A$. thaliana and rice. Expression profile analysis showed that the PePAP genes have different expression patterns in different Moso bamboo tissues. The expression of PePAP10, 12 and 16 genes in the root organs of Moso bamboo has a significant correlation with the activity of PAPs. Our study showed that PePAPs play an important role in the growth and development of plants under low-phosphorus stress and can provide a reference for revealing the low-phosphorus adaptation mechanism of Moso bamboo. In particular, the PePAP10 gene may be further used as a key candidate gene in Moso bamboo genetic engineering breeding.

Supplementary Materials: The following are available online at https:/ /www.mdpi.com/1999-490 7/12/3/326/s1, Table S1: Fluorescent quantitative primers of Moso bamboo, Table S2: The PePAP protein sequence of Moso bamboo, A. thaliana and rice. 
Author Contributions: Conceptualization, X.H. and M.L.; formal analysis, M.Z. (Mengyan Zhou) and W.C.; funding acquisition, M.L.; investigation, M.Z. (Mengyan Zhou), W.C., M.Z. (Mingzhen Zhao) and Y.L.; methodology, M.Z. (Mengyan Zhou), W.C., M.Z. (Mingzhen Zhao), Y.L., X.H. and M.L.; supervision, M.L.; validation, M.Z. (Mingzhen Zhao); visualization, M.Z. (Mingzhen Zhao); writingoriginal draft, M.Z. (Mengyan Zhou); writing—review and editing, M.Z. (Mengyan Zhou) and M.L. All authors have read and agreed to the published version of the manuscript.

Funding: This work was financially supported by the Science Foundation for The Excellent Youth Scholars of Fujian Agriculture and Forestry University (KXJQ19015) and Research Funding of Fujian Provincial Colleges and University Engineering Research Center of Sustainable Plantation.

Acknowledgments: We thank the reviewers and editors for their work.

Conflicts of Interest: The authors declare no conflict of interest.

\section{References}

1. Wang, T.T.; Li, Q.Z.; Lou, S.T.; Yang, Y.; Peng, L.F.; Lin, Z.Z.; Hu, Q.; Ma, L.Y. GSK3/shaggy-like kinase 1 ubiquitously regu-lates cell growth from A. to Moso bamboo (Phyllostachys edulis). Plant Sci. 2019, 283, 290-300. [CrossRef]

2. Wang, T.; Yang, Y.; Lou, S.; Wei, W.; Zhao, Z.; Ren, Y.; Lin, C.; Ma, L. Genome-Wide Characterization and Gene Expression Analyses of GATA Transcription Factors in Moso Bamboo (Phyllostachys edulis). Int. J. Mol. Sci. 2019, 21, 14. [CrossRef] [PubMed]

3. Sheng, Y.Z.; Fang, L.; Yu, L.Z.; Liang, H.Q.; Fang, Z.G.; Hui, P. Structural variability and differentiation of niches in the rhizosphere and endosphere bacterial microbiome of moso bamboo (Phyllostachys edulis). Sci. Rep. 2021, 11, 1-9.

4. Feder, D.; McGeary, R.P.; Mitić, N.; Lonhienne, T.; Furtado, A.; Schulz, B.L.; Henry, R.J.; Schmidt, S.; Guddat, L.W.; Schenk, G. Structural elements that modulate the substrate specificity of plant purple acid phosphatases: Avenues for improved phosphorus acquisition in crops. Plant Sci. 2020, 294, 110445. [CrossRef]

5. Rubio, V.; Linhares, F.; Solano, R.; Martín, A.C.; Iglesias, J.; Leyva, A.; Paz-Ares, J. A conserved MYB transcription factor involved in phosphate starvation signaling both in vascular plants and in unicellular algae. Cold Spring Harbor Laboratory Press 2001, 15, 2122-2133. [CrossRef] [PubMed]

6. Abel, S.; Ticconi, C.A.; Delatorre, C.A. Phosphate sensing in higher plants. Physiol. Plant. 2002, 115, 1-8. [CrossRef]

7. Robinson, W.D.; Carson, I.; Ying, S.; Ellis, K.; Plaxton, W.C. Eliminating the purple acid phosphatase At PAP 26 in A. thaliana delays leaf senescence and impairs phosphorus remobilization. New Phytol. 2012, 196, 1024-1029. [CrossRef] [PubMed]

8. Rashid, M.H.U.; Tigabu, M.; Chen, H.; Farooq, T.H.; Ma, X.; Wu, P. Calcium-mediated adaptive responses to low phosphorus stress in Chinese fir. Trees 2020, 34, 825-834. [CrossRef]

9. Li, J.; Luo, D.; Ma, G.; Jia, L.; Xu, J.; Huang, H.; Tong, Z.; Lu, Y.-Q. Response of Chinese fir seedlings to low phosphorus stress and analysis of gene expression differences. J. For. Res. 2018, 30, 183-192. [CrossRef]

10. Li, J.Z.; Xie, Y.; Dai, A.Y.; Liu, L.F.; Li, Z.C. Root and shoot traits responses to phosphorus deficiency and QTL analysis at seed-ling stage using introgression lines of rice. J. Genet. Genom. = Yi Chuan Xue Bao 2009, 36, 173-183. [CrossRef]

11. Li, C.; Cai, Y.; Xiao, L.; Gao, X.; Shi, Y.; Du, H.; Zhou, Y.; Zhou, G. Effects of different planting approaches and site conditions on aboveground carbon storage along a 10-year chronosequence after moso bamboo reforestation. For. Ecol. Manag. 2021, 482, 118867. [CrossRef]

12. Deng, S.; Lu, L.; Li, J.; Du, Z.; Liu, T.; Li, W.; Xu, F.; Shi, L.; Shou, H.; Wang, C. Purple acid phosphatase 10c encodes a major acid phosphatase that regulates plant growth under phosphate-deficient conditions in rice. J. Exp. Bot. 2020, 71, 4321-4332. [CrossRef]

13. Zhu, X.L.; Lee, S.Y.; Yang, W.T.; Lee, S.W.; Baek, D.; Li, M.S.; Kim, D.H. The Burholderia pyrrocinia Purple Acid Phosphatase Pap9 Mediates Phosphate Acquisition in Plants. J. Plant Biol. 2019, 62, 342-350. [CrossRef]

14. Wang, Y.; Yang, Z.; Kong, Y.; Li, X.; Li, W.; Du, H.; Zhang, C. GmPAP12 Is Required for Nodule Development and Nitrogen Fixation Under Phosphorus Starvation in Soybean. Front. Plant Sci. 2020, 11, 11. [CrossRef] [PubMed]

15. Shen, J.; Yuan, L.; Zhang, J.; Li, H.; Bai, Z.; Chen, X.; Zhang, W.; Zhang, F. Phosphorus Dynamics: From Soil to Plant. Plant Physiol. 2011, 156, 997-1005. [CrossRef] [PubMed]

16. Gao, W.; Lu, L.; Qiu, W.; Wang, C.; Shou, H. OsPAP26 Encodes a Major Purple Acid Phosphatase and Regulates Phosphate Remobilization in Rice. Plant Cell Physiol. 2017, 58, 885-892. [CrossRef]

17. Tran, H.T.; Hurley, B.A.; Plaxton, W.C. Feeding hungry plants: The role of purple acid phosphatases in phosphate nutrition. Plant Sci. 2010, 179, 14-27. [CrossRef]

18. Jersey, J.D.; Zheng, Y.Z.; Fan, H.K.; Gary, S.; Luke, G.; Hamilton, S. Mammalian-like Purple Acid Phosphatases in Plants. Chem. Res. Chin. Univ. 2006, 22, 263-264.

19. The Role of Intracellular and Secreted Purple Acid Phosphatases in Plant Phosphorus Scavenging and Recycling; Plaxton, W.C.; Lambers, H., Eds.; John Wiley \& Sons, Inc.: Hoboken, NJ, USA, 2015; pp. 265-287.

20. Neumann, G.; Römheld, V. Root excretion of carboxylic acids and protons in phosphorus-deficient plants. Plant Soil 1999, 211, 121-130. [CrossRef] 
21. Liang, C.; Tian, J.; Lam, H.-M.; Lim, B.L.; Yan, X.; Liao, H. Biochemical and Molecular Characterization of PvPAP3, a Novel Purple Acid Phosphatase Isolated from Common Bean Enhancing Extracellular ATP Utilization. Plant Physiol. 2009, 152, 854-865. [CrossRef] [PubMed]

22. Olczak, M.; Morawiecka, B.; Watorek, W. Plant purple acid phosphatases-Genes, structures and biological function. Acta Biochim. Pol. 2003, 50, 1245-1256. [CrossRef]

23. Del Vecchio, H.A.; Ying, S.; Park, J.; Knowles, V.L.; Kanno, S.; Tanoi, K.; She, Y.-M.; Plaxton, W.C. The cell wall-targeted purple acid phosphatase AtPAP25 is critical for acclimation of A. thaliana to nutritional phosphorus deprivation. Plant J. Cell Mol. Biol. 2014, 80, 569-581. [CrossRef]

24. Zimmermann, P.; Regierer, B.; Kossmann, J.; Frossard, E.; Amrhein, N.; Bucher, M. Differential Expression of Three Purple Acid Phosphatases from Potato. Plant Biol. 2004, 6, 519-528. [CrossRef]

25. Wang, L.S.; Lu, S.; Zhang, Y.; Li, Z.; Du, X.Q.; Liu, D. Comparative genetic analysis of A. purple acid phosphatases AtPAP10, AtPAP12, and AtPAP26 provides new insights into their roles in plant adaptation to phosphate deprivation. J. Integr. Plant Biol. 2014, 56, 299-314. [CrossRef]

26. Zhang, Q.; Wang, C.; Tian, J.; Li, K.; Shou, H. Identification of rice purple acid phosphatases related to phosphate starvation signalling. Plant Biol. 2011, 13, 1. [CrossRef]

27. Li, C.; Gui, S.; Yang, T.; Walk, T.; Wang, X.; Liao, H. Identification of soybean purple acid phosphatase genes and their expression responses to phosphorus availability and symbiosis. Ann. Bot. 2011, 109, 275-285. [CrossRef] [PubMed]

28. Sun, F.; Suen, P.K.; Zhang, Y.; Liang, C.; Carrie, C.; Whelan, J.; Ward, J.L.; Hawkins, N.D.; Jiang, L.; Lim, B.L. A dual-targeted purple acid phosphatase in $A$. thaliana moderates carbon metabolism and its overexpression leads to faster plant growth and higher seed yield. New Phytol. 2012, 194, 206-219. [CrossRef] [PubMed]

29. Zhang, W.Y.; Gruszewski, H.A.; Chevone, B.I.; Nessler, C.L. An A. Purple Acid Phosphatase with Phytase Activity Increases Foliar Ascorbate. Plant Physiol. 2008, 146, 431-440. [CrossRef]

30. Sridhar, R.; Sophia, L.S.; Bernhard, B.; Balakrishnan, P. Purple Acid Phosphatase5 is required for maintaining basal resistance against Pseudomonas syringae in A. BMC Plant Biol. 2013, 13, 107.

31. Baskar, V.; Dhivya, S.; Sathishkumar, R. Genome-wide analysis of purple acid phosphatase (PAP) family proteins in Jatropha curcas L. Int. J. Biol. Macromol. 2018, 123, 648-656.

32. Zhang, T.; Ding, G.J.; Wen, X.P. Cloning and expression pattern analysis of ectomycorrhizal purple acid phosphatase gene in Pinus massoniana Lamb. For. Res. Beijing 2016, 29, 797-806.

33. Liu, Y.; Wu, C.; Hu, X.; Gao, H.; Wang, Y.; Luo, H.; Cai, S.; Li, G.; Zheng, Y.; Lin, C.; et al. Transcriptome profiling reveals the crucial biological pathways involved in cold response in Moso bamboo (Phyllostachys edulis). Tree Physiol. 2019, 40, 538-556. [CrossRef]

34. Peng, Z.; Lu, Y.; Li, L.; Zhao, Q.; Feng, Q.; Gao, Z.; Lu, H.; Hu, T.; Yao, N.; Liu, K.; et al. The draft genome of the fast-growing non-timber forest species moso bamboo (Phyllostachys heterocycla). Nat. Genet. 2013, 45, 456-461. [CrossRef]

35. Lozano, R.; Hamblin, M.T.; Prochnik, S.; Jannink, J.L. Identification and distribution of the NBS-LRR gene family in the Cassava genome. BMC Genom. 2015, 16, 1-14. [CrossRef]

36. Guo, A.-Y.; Zhu, Q.-H.; Chen, X.; Luo, J.-C. GSDS: A gene structure display server. Hereditas 2007, 29, 1023-1026. [CrossRef]

37. Yang, Y.; Kang, L.; Wu, R.H.; Chen, Y.Z.; Lu, C.F. Genome-wide identification and characterization of UDP-glucose dehydrogenase family genes in moso bamboo and functional analysis of PeUGDH4 in hemicellulose synthesis. Sci. Rep. 2020, 10, 10124. [CrossRef]

38. Wu, W.; Lin, Y.; Liu, P.; Chen, Q.; Tian, J.; Liang, C. Association of extracellular dNTP utilization with a GmPAP1-like protein identified in cell wall proteomic analysis of soybean roots. J. Exp. Bot. 2018, 69, 603-617. [CrossRef]

39. Thompson, J.D.; Gibson, T.J.; Plewniak, F.; Jeanmougin, F.; Higgins, D.G. The CLUSTAL_X windows interface: Flexible strategies for multiple sequence alignment aided by quality analysis tools. Nucleic Acids Res. 1997, 25, 4876-4882. [CrossRef]

40. Sudhir, K.; Glen, S.; Koichiro, T. MEGA7: Molecular evolutionary genetics analysis version 7.0 for bigger datasets. Mol. Biol. Evol. 2016, 33, 1870-1874.

41. Bailey, T.L.; Williams, N.; Misleh, C.; Li, W.W. MEME: Discovering and analyzing DNA and protein sequence motifs. Nucleic Acids Res. 2006, 34, W369-W373. [CrossRef]

42. Hu, B.; Jin, J.; Guo, A.-Y.; Zhang, H.; Luo, J.; Gao, G. GSDS 2.0: An upgraded gene feature visualization server. Bioinformatics 2015, 31, 1296-1297. [CrossRef]

43. Chang, Y.; Song, X.; Zhang, Q.; Liu, H.; Bai, Y.; Lei, X.; Pei, D. Genome-Wide Identification of WOX Gene Family and Expression Analysis during Rejuvenational Rhizogenesis in Walnut (Juglans regia L.). Forests 2019, 11, 16. [CrossRef]

44. Livak, K.J.; Schmittgen, T.D. Analysis of relative gene expression data using real-time quantitative PCR and the 2(-delta delta c (t)) method. Methods 2001, 25, 402-408. [CrossRef] [PubMed]

45. Zhu, S.N.; Chen, M.H.; Liang, C.Y.; Xue, Y.B.; Lin, S.L.; Tian, J. Characterization of Purple Acid Phosphatase Family and Functional Analysis of GmPAP7a / 7b Involved in Extracellular ATP Utilization in Soybean. Front. Plant Sci. 2020, 11, 661. [CrossRef]

46. Yin, C.; Wang, F.; Fan, H.; Fang, Y.; Li, W. Identification of Tea Plant Purple Acid Phosphatase Genes and Their Expression Responses to Excess Iron. Int. J. Mol. Sci. 2019, 20, 1954. [CrossRef] [PubMed]

47. Kong, Y.; Li, X.; Ma, J.; Li, W.; Yan, G.; Zhang, C. GmPAP4, a novel purple acid phosphatase gene isolated from soybean (Glycine max), enhanced extracellular phytate utilization in A. thaliana. Plant Cell Rep. 2014, 33, 655-667. [CrossRef] [PubMed] 
48. Li, C.; Zhou, J.; Wang, X.; Liao, H. A purple acid phosphatase, GmPAP33, participates in arbuscule degeneration during arbuscular mycorrhizal symbiosis in soybean. Plant Cell Environ. 2019, 42, 2015-2027. [CrossRef]

49. Kuang, R.; Chan, K.-H.; Yeung, E.; Lim, B.L. Molecular and Biochemical Characterization of AtPAP15, a Purple Acid Phosphatase with Phytase Activity, in A. Plant Physiol. 2009, 151, 199-209. [CrossRef]

50. Dionisio, G.; Madsen, C.K.; Holm, P.B.; Welinder, K.G.; Jørgensen, M.; Stoger, E.; Arcalis, E.; Brinch-Pedersen, H. Cloning and Characterization of Purple Acid Phosphatase Phytases from Wheat, Barley, Maize, and Rice. Plant Physiol. 2011, 156, 1087-1100. [CrossRef]

51. Bhadouria, J.; Singh, A.P.; Mehra, P.; Verma, L.; Srivastawa, R.; Parida, S.K.; Giri, J. Identification of Purple Acid Phosphatases in Chickpea and Potential Roles of CaPAP7 in Seed Phytate Accumulation. Sci. Rep. 2017, 7, 1-12. [CrossRef]

52. Rajat, S.; Akash, P.; Parida, A.; Kumar, C.P.; Rahul, K. Identification, structure analysis, and transcript profiling of purple acid phosphatases under Pi deficiency in tomato (Solanum lycopersicum L.) and its wild relatives. Int. J. Biol. Macromol 2020, 165, 2253-2266.

53. Föhse, D.; Claassen, N.; Jungk, A. Phosphorus efficiency of plants. Plant Soil 1991, 132, 261-272. [CrossRef]

54. Anghinoni, I.; Barber, S.A. Phosphorus Influx and Growth Characteristics of Corn Roots as Influenced by Phosphorus Supply 1. Agron. J. 1980, 72, 685-688. [CrossRef]

55. Barber, S.; Mackay, A. Root growth and phosphorus and potassium uptake by two corn genotypes in the field. Nutr. Cycl. Agroecosyst. 1986, 10, 217-230. [CrossRef]

56. Doris, F.; Claassen, N.; Jungk, A. Phosphorus efficiency of plants: I. External and internal P requirement and P uptake efficiency of different plant species. Plant Soil 1988, 110, 101-109.

57. Dinkelaker, B.; Romheld, V.; Marschner, H. Citric acid excretion and precipitation of calcium citrate in the rhizosphere of white lupin (Lupinus albus L.). Plant Cell Environ. 1989, 12, 285-292. [CrossRef]

58. McLachlan, J.W.; Becquer, A.; Haling, R.E.; Simpson, R.J.; Flavel, R.J.; Guppy, C.N. Intrinsic root morphology determines the phosphorus acquisition efficiency of five annual pasture legumes irrespective of mycorrhizal colonisation. Funct. Plant Biol. 2020, 48, 156-170. [CrossRef]

59. Vance, C.P.; Uhde-Stone, C.; Allan, D.L. Phosphorus acquisition and use: Critical adaptations by plants for securing a nonrenewable resource. New Phytol. 2003, 157, 423-447. [CrossRef]

60. Lu, L.; Qiu, W.; Gao, W.; Tyerman, S.D.; Shou, H.; Wang, C. OsPAP10c, a novel secreted acid phosphatase in rice, plays an important role in the utilization of external organic phosphorus. Plant Cell Environ. 2016, 39, 2247-2259. [CrossRef]

61. Li, C.; Li, C.; Zhang, H.; Liao, H.; Wang, X. The purple acid phosphatase GmPAP21 enhances internal phosphorus utilization and possibly plays a role in symbiosis with rhizobia in soybean. Physiol. Plant. 2017, 159, 215-227. [CrossRef] [PubMed]

62. Li, W.-Y.F.; Shao, G.; Lam, H.-M. Ectopic expression of GmPAP3 alleviates oxidative damage caused by salinity and osmotic stresses. New Phytol. 2008, 178, 80-91. [CrossRef] [PubMed]

63. Liao, H.; Wong, F.-L.; Phang, T.-H.; Cheung, M.-Y.; Li, W.-Y.F.; Shao, G.; Yan, X.; Lam, H.-M. GmPAP3, a novel purple acid phosphatase-like gene in soybean induced by $\mathrm{NaCl}$ stress but not phosphorus deficiency. Gene 2003, 318, 103-111. [CrossRef]

64. Eliécer, G.M.; Aida-Odette, A.V.; Chávez, M.R.A.; Stefan, D.F.; Liliana, A.H.; Cei, A.G.; Sawers, R.J.H. The maize (Zea mays ssp. mays var. B73) genome encodes 33 members of the purple acid phosphatase family. Front. Plant Sci. 2015, 6, 341.

65. Zhu, H.F.; Qian, W.Q.; Lu, X.Z.; Li, D.P.; Liu, X.; Liu, K.F.; Wang, D.W. Expression Patterns of Purple Acid Phosphatase Genesin A. Organs and Functional Analysis of AtPAP23 Predominantly Transcribed in Flower. Plant Mol. Biol. 2005, 59, 581-594. [CrossRef] [PubMed] 